\title{
Eosinophilic Granulomatosis With Polyangiitis (Churg-Strauss Syndrome) Mimicking a Stroke and Acute Coronary Syndrome: A Case Report
}

\author{
Uzma Ishaq ${ }^{1}$, Jahanzeb Malik ${ }^{2}$, Adnan Baig ${ }^{2}$, Muhammad Javaid ${ }^{2}$, Umar Ikram ${ }^{2}$ \\ 1. Hematology and Medical Oncology, Fauji Foundation Hospital, Rawalpindi, PAK 2. Cardiology, Rawalpindi Institute \\ of Cardiology, Rawalpindi, PAK
}

Corresponding author: Jahanzeb Malik, heartdoc86@gmail.com

\begin{abstract}
Churg-Strauss syndrome (CSS) is a rare disease of multiple organ involvement attributed to asthma, eosinophilia, and vasculitis as a diagnostic criterion. Here we report a case of CSS presenting with left leg weakness and chest pain with a diagnosis of myocarditis and neuropathy. Eosinophilia, history of asthma, peripheral neurological damage led to the diagnosis of CSS. Transthoracic echo showed a full-sized segmental wall motion abnormality with normal CT angiography. He responded well to steroid therapy.
\end{abstract}

Received 06/24/2020 Review began 06/27/2020 Review ended 06/27/2020 Published 07/03/2020

() Copyright 2020 Ishaq et al. This is an open access article distributed under the terms of the Creative Commons Attribution License CC-BY 4.0., which permits unrestricted use, distribution, and reproduction in any medium, provided the original author and source are credited.
Categories: Cardiology, Allergy/Immunology, Hematology

Keywords: churg-strauss syndrome, eosinophilic granulomatosis with polyangiitis, eosinophilia, hypereosinophilia, hypereosinophilia syndrome, myocarditis, acute coronary syndrome, rituximab

\section{Introduction}

Eosinophilic granulomatosis with polyangiitis, also known as Churg-Strauss syndrome (CSS), was first reported in 1951 [1]. It is characterized by a triad of hypereosinophilia, asthma, and necrotizing vasculitis of small to medium arteries in people with a history of atopy [2]. This disease manifests in the third and fourth decade of life affecting both males and females equally [3]. The etiology of CSS is still unknown. It's likely that a combination of genes and environmental factors, such as allergens or certain medications, triggers an overactive immune system response.

Asthma is the characteristic finding of this syndrome. Lungs are involved frequently with variable involvement of cardiac, vascular, nervous, and renal systems [4]. Cardiovascular system is involved in $30 \%$ of CSS cases presenting as pericarditis, pericardial effusion, valvular Loeffler's endocarditis, myocarditis, stroke, heart failure, and myocardial infarction [5]. This is uncommon but cardiac involvement is a major cause of morbidity and mortality in CSS.

Here we report a case of CSS presenting with chest pain and left leg weakness, mimicking acute myocardial infarction, and a stroke.

\section{Case Presentation}

A 48-year-old man with a prolonged history of asthma and general fatigue was admitted with three days history of severe, central chest pain radiating to the left arm and jaw. It was relieved by analgesics. He also complained of left-sided lower limb weakness for one day. The patient had no comorbidity.

At presentation, he was accelerated through triage and shifted to coronary care bay for assessment. His blood pressure was $95 / 60 \mathrm{mmHg}$ with a pulse of 90 beats/min. The chest was clear to auscultation with prolonged expiration and no murmur, rub, or gallop was appreciated on cardiovascular examination. Upper limb power was $5 / 5$ with normal reflexes. In lower limbs, power was $5 / 5$ and 3/5 in right and left leg, respectively. He was suspected of acute coronary syndrome and stroke.

ECG was ordered which is shown in Figure 1. 


\section{Cureus}

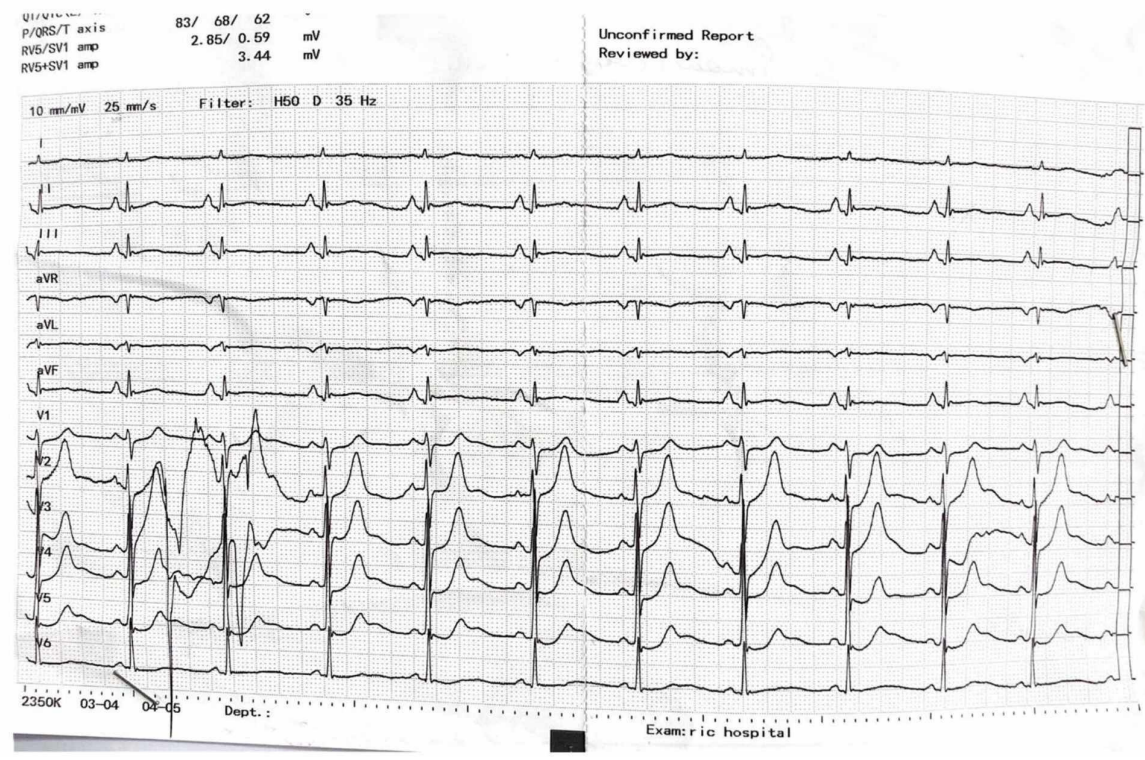

FIGURE 1: ECG of the patient

Level of troponin I was $6 \mathrm{ng} / \mathrm{mL}$ (normally less than $0.5 \mathrm{ng} / \mathrm{mL}$ ) and cardiac enzymes were elevated (CK-MB $56 \mathrm{IU} / \mathrm{L}, \mathrm{CK} 252 \mathrm{IU} / \mathrm{L}$ ). His white blood count was $20 \times 10^{9} / \mathrm{L}$ and there was eosinophilia with a cell count of $4.5 \times 10^{9} / \mathrm{L}$ and $56 \%$ leukocytes. Hypersensitive C-reactive protein (hsCRP) was $23 \mathrm{mg} / \mathrm{dL}$ (normally less than $0.35 \mathrm{mg} / \mathrm{dL}$ ). Considering his history of asthma, his B-type natriuretic peptide (BNP) was ordered which came out to be $430 \mathrm{pg} / \mathrm{mL}$ (normally less than $70 \mathrm{pg} / \mathrm{mL}$ ) and D-dimer level was $1200 \mu \mathrm{g} / \mathrm{L}$ (normally less than 550 $\mu \mathrm{g} / \mathrm{L}$ ). Transthoracic echocardiography showed a full-sized and hypokinetic left ventricle with an ejection fraction of 30\%. There were severe segmental hypokinesia in the anterior, septal, and apical segments. Echocardiogram for wall motion abnormality is shown in Video 1 .

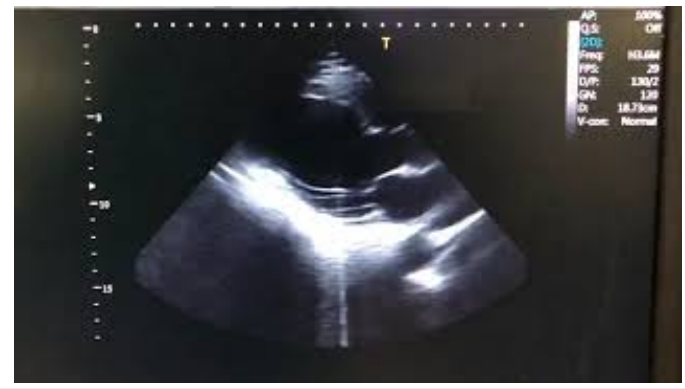

\section{VIDEO 1: Wall motion hypokinesia in apical and septal segments}

View video here: https://www.youtube.com/watch?v=MEMoOPZqzGA

CT scan brain is shown in Figure 2 which was normal. 


\section{Cureus}

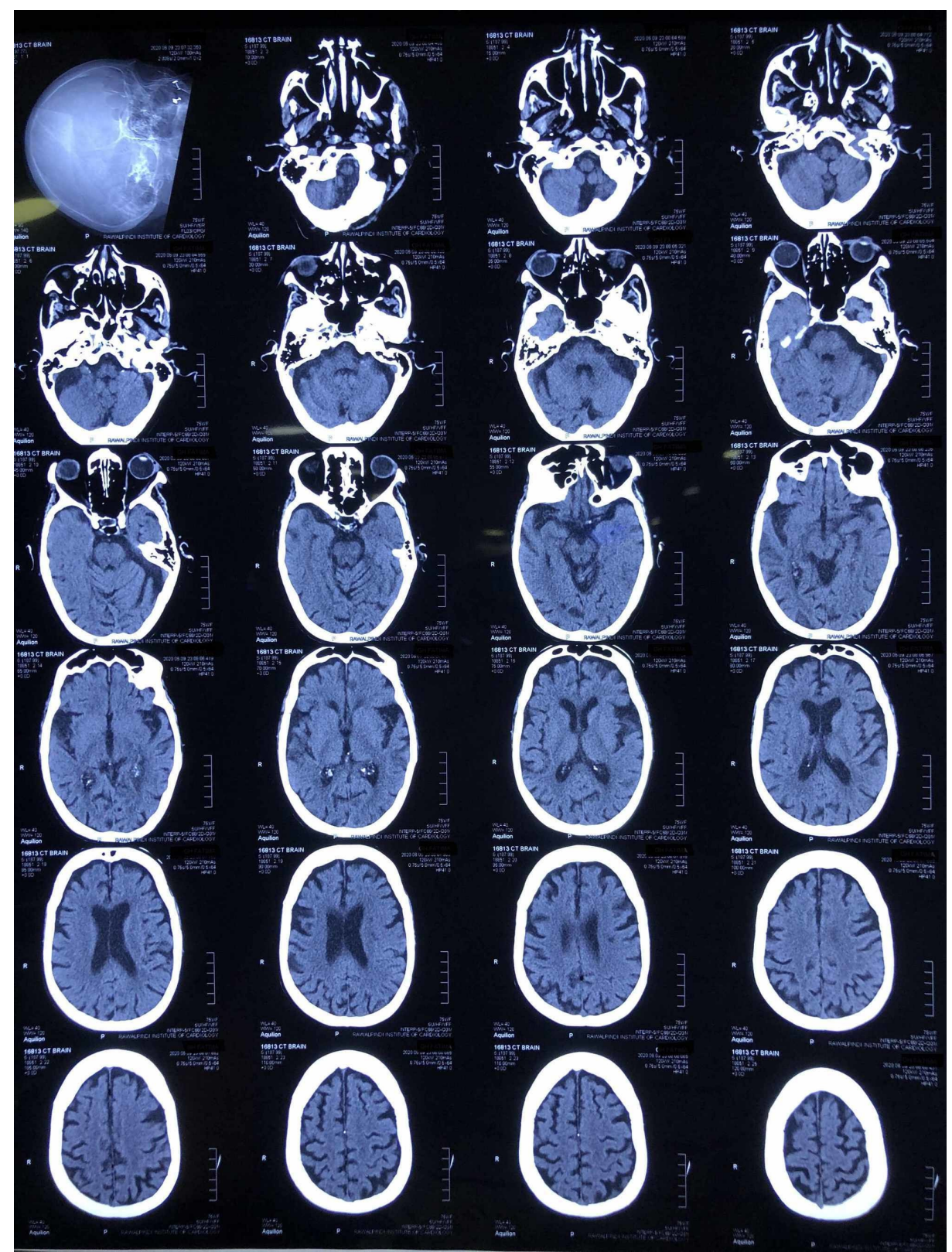

FIGURE 2: CT scan brain of the patient

Chest X-ray is shown in Figure 3. It shows no unusual findings. 


\section{Cureus}

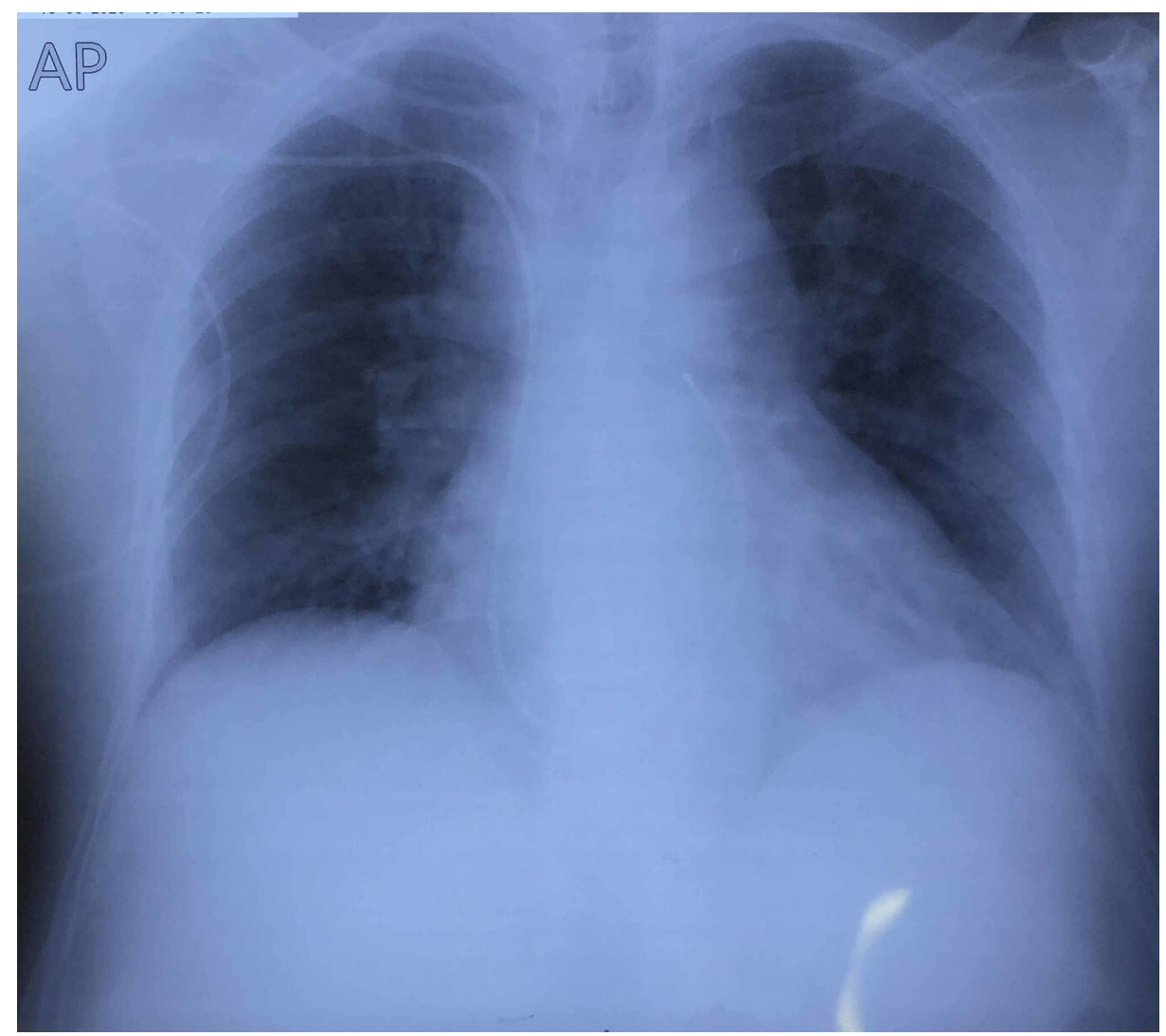

FIGURE 3: Chest X-ray of the patient

According to his Global Registry of Acute Coronary Events (GRACE) score of less than 140, he was treated as low risk acute coronary syndrome and his $\mathrm{CT}$ angiography was done showing essentially non-obstructive coronary artery disease (Videos 2-4).

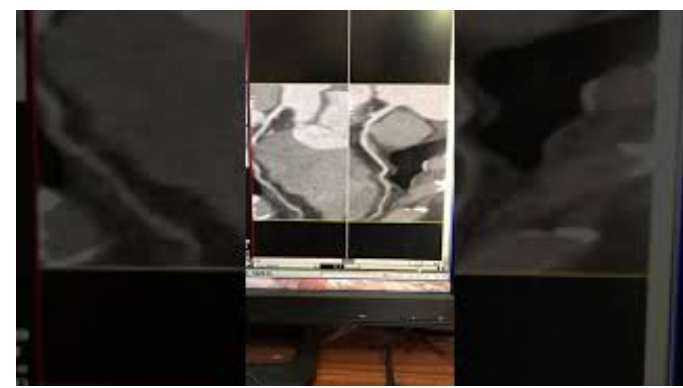

VIDEO 2: Left anterior descending artery

View video here: https://www.youtube.com/watch?v=B8dGal3UJTg

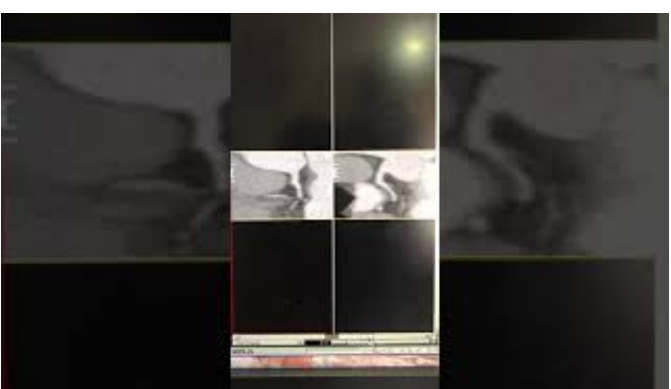

VIDEO 3: Left circumflex artery

View video here: https://www.youtube.com/watch?v=cVD4m5ZQVTM 


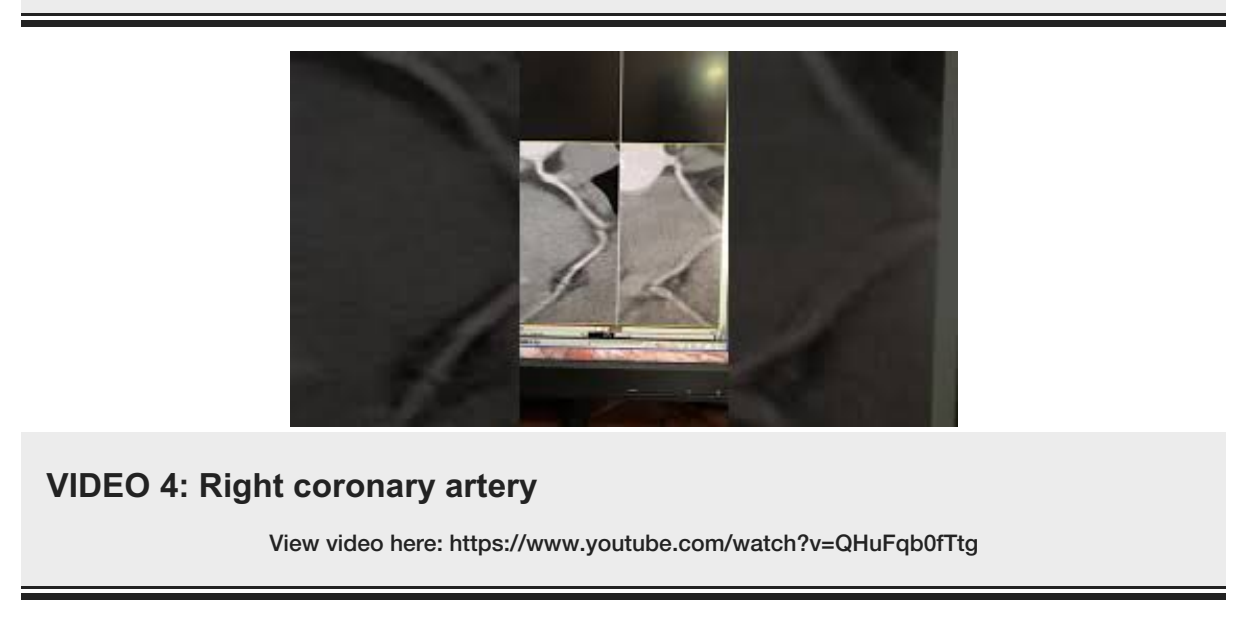

Thallium scan revealed multiple perfusion defects in the left ventricle and left ventricle ejection fraction was reduced. On this, a diagnosis of myocarditis was made associated with CSS. Neurology department gave a diagnosis of neuropathy on nerve conduction studies.

Hematology consult was called and his peripheral smear and bone marrow biopsy done which revealed reactive eosinophilia and thrombocytosis. Serum tests were negative for anti-double-stranded DNA (dsDNA) and anti-neutrophil cytoplasmic antibodies (ANCA). Viral serology was also negative for hepatitis B and C, HIV, and Epstein-Barr virus. The diagnosis of CSS was contemplated given the history of asthma and extravascular eosinophilia. Immunosuppressive therapy was started with prednisolone $1 \mathrm{mg} / \mathrm{kg}$ upon diagnosis along with single antiplatelet therapy with aspirin $75 \mathrm{mg}$ once daily. Guide-line directed medical therapy (GDMT) for heart failure was also started. After treatment, his symptoms improved and limb weakness decreased and gradually power became $4 / 5$ at two weeks. His troponin I and hs-CRP levels became normal. Eosinophilia decreased to normal in peripheral smear. The patient was discharged from the hospital on aspirin, ramipril, metoprolol, spironolactone, and prednisolone. One month after diagnosis, the patient was asymptomatic and his repeat echo showed an improved ejection fraction of $50 \%$.

\section{Discussion}

CSS is a rare autoimmune disease with an international incidence of less than 2.5 cases per 100,000 adults per year [6]. It is diagnosed if four principle signs are present: a) asthma, b) hypereosinophilia with an eosinophil count of more than $1.5 \times 10^{9} / \mathrm{L}, \mathrm{c}$ ) vasculitis-induced neuropathy, d) migratory or unfixed pulmonary infiltrates, e) paranasal sinus abnormalities, f) extravascular eosinophils on histology and biopsy [7]. Frequently, eosinophilic infiltrates and necrotizing granulomas are also observed [8].

The pathophysiology of CSS is divided into three stages. At first, there is the prodromal stage which is associated with atopy and asthma. It can last for as long as 30 years, according to a report. In the next stage, there is tissue infiltration of eosinophils in the lungs and myocardium. In the final stage, usually, the diagnosis is made and it presents as a vasculitis. Many factors including genes, atopy, drugs, infection, and vaccinations have been implicated with CSS. Dysregulated immune function has been associated with increased eosinophils [9].

Cardiac involvement is very rare but one of the most serious manifestations, accounting for one-half of the deaths associated with CSS [10]. It can be acute, mimicking acute coronary syndrome and it may present in a variety of ways [3]. Myocarditis is another form of cardiac manifestations of CSS, presenting as chest pain, arrhythmias, or cardiogenic shock. Some reports suggest an increased risk of myocarditis in young adults between the ages of 20 to 30 years [11]. There is a marked increase in eosinophil counts in patients with myocarditis, according to some reports [12]. Patients' CRP is increased showing an inflammatory response. However, usually, they are ANCA negative [13].

Immunosuppression therapy remains the mainstay of treatment for CSS and corticosteroids are the first-line therapy, which increases survival [14]. In severe recurrent disease, cyclophosphamide or rituximab can be used $[15,16]$. In our patient, he responded well to steroids and remained in remission after a one-month follow-up.

\section{Conclusions}

Being a rare multisystem disease, cardiac manifestations confer increased mortality and morbidity in CSS. Younger females have more incidence of cardiac involvement than older men, and a history of asthma is strongly associated with myocarditis. Markedly increased eosinophil counts are seen in myocarditis than with other organ system involvement and heart disease in CSS is associated with negative ANCA status. As demonstrated by our case, CSS can present as acute coronary syndrome and it can have neurological 
sequelae.

\section{Additional Information \\ Disclosures}

Human subjects: Consent was obtained by all participants in this study. Conflicts of interest: In compliance with the ICMJE uniform disclosure form, all authors declare the following: Payment/services info: All authors have declared that no financial support was received from any organization for the submitted work. Financial relationships: All authors have declared that they have no financial relationships at present or within the previous three years with any organizations that might have an interest in the submitted work. Other relationships: All authors have declared that there are no other relationships or activities that could appear to have influenced the submitted work.

\section{References}

1. Churg J, Strauss L: Allergic granulomatosis, allergic angiitis, and periarteritis nodosa . Am J Pathol. 1951, 27:277-301.

2. Comarmond C, Pagnoux C, Khellaf M, et al.: Eosinophilic granulomatosis with polyangiitis (Churg-Strauss): clinical characteristics and long-term followup of the 383 patients enrolled in the French Vasculitis Study Group cohort. Arthritis Rheum. 2013, 65:270-281. 10.1002/art.37721

3. Moore P, Toon LT: Eosinophilic granulomatosis with polyangiitis (Churg-Strauss syndrome) masquerading as acute coronary syndrome. Clin Med J (Lond). 2020, 20:s51. 10.7861/clinmed.20-2-s51

4. Cottin V, Bel E, Bottero P, et al.: Respiratory manifestations of eosinophilic granulomatosis with polyangiitis (Churg-Strauss). Eur Respir J. 2016, 48:1429-1441. 10.1183/13993003.00097-2016

5. Durel CA, Berthiller J, Caboni S, Jayne D, Ninet J, Hot A: Long-term followup of a multicenter cohort of 101 patients with eosinophilic granulomatosis with polyangiitis (Churg-Strauss). Arthritis Care Res. 2016, 68:374-387. 10.1002/acr.22686

6. Mohammad AJ: An update on the epidemiology of ANCA-associated vasculitis . Rheumatology (Oxford). 2020, 59:42-50. 10.1093/rheumatology/keaa089

7. Santos YA, Silva BR, Lira PN, Vaz LC, Mafort TT, Bruno LP, Lopes AJ: Eosinophilic granulomatosis with polyangiitis (formerly known as Churg-Strauss syndrome) as a differential diagnosis of hypereosinophilic syndromes. Respir Med Case Rep. 2017, 21:1-6. 10.1016/j.rmcr.2017.03.006

8. Plumb LA, Oni L, Marks SD, Tullus K: Paediatric anti-neutrophil cytoplasmic antibody (ANCA)-associated vasculitis: an update on renal management. Pediatr Nephrol. 2018, 33:25-39. 10.1007/s00467-016-3559-2

9. Vaglio A, Buzio C, Zwerina J: Eosinophilic granulomatosis with polyangiitis (Churg-Strauss): state of the art. Allergy. 2013, 68:261-273. 10.1111/all.12088

10. Chaudhry MA, Grazette L, Yoon A, Correa A, Fong MW: Churg-Strauss syndrome presenting as acute necrotizing eosinophilic myocarditis: concise review of the literature. Curr Hypertens Rev. 2019, 15:8-12. 10.2174/1573402114666180903164900

11. Bluett R, McDonnell D, O'Dowling C, Vaughan C: Eosinophilic myocarditis as a first presentation of eosinophilic granulomatosis with polyangiitis (Churg-Strauss syndrome). BMJ Case Rep. 2017, 2017 :bcr2017-221227. 10.1136/bcr-2017-221227

12. Leurs A, Chenivesse C, Lopez B, et al.: C-Reactive protein as a diagnostic tool in differential diagnosis of hypereosinophilic syndrome and antineutrophil cytoplasmic antibody-negative eosinophilic granulomatosis with polyangiitis. J Allergy Clin Immunol Pract. 2019, 7:1347-1351. 10.1016/j.jaip.2018.10.002

13. d'Ersu E, Ribi C, Monney P, et al.: Churg-Strauss syndrome with cardiac involvement: case illustration and contribution of CMR in the diagnosis and clinical follow-up. Int J Cardiol. 2018, 258:321-324. 10.1016/j.ijcard.2018.02.011

14. Cho HJ, Yune S, Seok JM, et al.: Clinical characteristics and treatment response of peripheral neuropathy in the presence of eosinophilic granulomatosis with polyangiitis (Churg-Strauss syndrome): experience at a single tertiary center. J Clin Neurol. 2017, 13:77-83. 10.3988/jcn.2017.13.1.77

15. Pagnoux C, Groh M: Optimal therapy and prospects for new medicines in eosinophilic granulomatosis with polyangiitis (Churg-Strauss syndrome). Expert Rev Clin Immunol. 2016, 12:1059-1067. 10.1080/1744666X.2016.1191352

16. Thiel J, Troilo A, Salzer U, et al.: Rituximab as induction therapy in eosinophilic granulomatosis with polyangiitis refractory to conventional immunosuppressive treatment: a 36-month follow-up analysis. J Allergy Clin Immunol Pract. 2017, 5:1556-1563. 10.1016/j.jaip.2017.07.027 